\title{
Resignificación del ocio: aportes para un aprendizaje transformacional
}

\section{Rodrigo Elizalde*}

\begin{abstract}
Resumen: Este artículo tiene como objetivo principal el repensar el ocio en las sociedades contemporáneas latinoamericanas, buscando generar aportes para su resignificación. Para esto, el ocio es abordado considerando sus vínculos con las emergentes realidades de la actualidad. Se empieza construyendo definiciones de lo que se entiende por ocio, basándose en los desarrollos teóricos ya existentes. Ampliando la perspectiva, se realiza un análisis crítico de la forma en que el ocio es percibido en el imaginario social latinoamericano actual. Posteriormente se analizan los avances y retrocesos sociales como indicadores que expresan la situación actual del ocio. Para concluir se elabora una primera propuesta en la cual el ocio será resignificado buscando la posibilidad de construir nuevos conocimientos y prácticas para un aprendizaje comprometido con la transformación social.
\end{abstract}

Palabras-clave: ocio, sociedades contemporáneas, América Latina, transformación social

\section{Resignificance of leisure: contributions for a transformational learning}

\begin{abstract}
This investigation has as principal aim to rethink leisure in contemporary Latin-American societies, seeking to generate contributions for its resignificance. For this, leisure is approached considering its links with emergent current realities. It starts by constructing definitions of what is understood by leisure, based on the theoretical already existing developments. Extending the perspective, a critical analysis of the form in which the leisure is perceived in the imaginary social current Latin American is presented. Later social advances and setbacks are analyzed as warnings that express the current situation of leisure. To conclude a first proposal is elaborated, in which the leisure will be re-signified looking for the possibility of constructing new knowledges and practices for a learning commited with the social transformation.
\end{abstract} transformation

Key words: leisure, contemporary societies, Latin America, social

\section{Resignificação do lazer: contribuições para uma aprendizagem transformacional}

Resumo: Este artigo tem como objetivo principal repensar o lazer nas so-

\footnotetext{
* Grupo de Pesquisa OTIUM: Lazer, Brasil \& América Latina (UFMG), Belo Horizonte, Brasil. E-mail: roelizalde@gmail.com
} 
ciedades contemporâneas latino-americanas, procurando gerar contribuições para a ressignificação deste fenômeno. O lazer é abordado considerando seus vínculos com as realidades emergentes da atualidade. Baseando-se em desenvolvimentos teóricos já existentes, o texto começa construindo definições do que se entende por lazer. Ampliando a perspectiva, realiza-se uma análise crítica da forma como o lazer é percebido no imaginário social latino-americano atual. Posteriormente, analisam-se os avanços e retrocessos sociais como indicadores que expressam a situação atual do lazer. Para concluir, elabora-se uma primeira proposta na qual o lazer será ressignificado, procurando possibilidades para construir novos conhecimentos e práticas para uma aprendizagem comprometida com a transformação social.

Palavras-chave: lazer, sociedades contemporâneas, América Latina, transformação social

Recibido: 26.10.2009

Aceptado: 09.12.2009

$* * *$

\section{Presentación}

Esta investigación busca discutir una temática, en general, subvalorada, poco estudiada y desconsiderada: El ocio ${ }^{1}$. Este es un concepto que en Latino América, en muchos casos, está cargado de prejuicios y connotaciones negativas y, que posiblemente puede causar sorpresa en algunas personas en cuanto objeto de estudio. Aquí, en cambio, profundizar en él es considerado como fundamental para repensar la realidad contemporánea, buscando aportar nuevas formas de entender los emergentes fenómenos sociales de la actualidad y ampliar la discusión comprometida con la transformación de nuestras sociedades, para que estas sean humanas y sustentables.

Como objetivo principal se plantea repensar el ocio en las sociedades latinoamericanas actuales, intentando generar aportes para su valoración ya que, equivocadamente, muchas veces, es considerado objeto irrelevante en el medio académico. Se acredita que existen cuestiones más nobles e importantes a ser investigadas, lo que revela un gran prejuicio (Magnani, 2000). Una de las razones principales para que esto ocurra puede ser el que tradicionalmente se confunde ocio con ociosidad y, consecuentemente, por esta vía se lo ve como sinónimo de la pereza y de hacer nada.

Paradojalmente con lo anterior, estudios de Arendt (1993) revelan que ya desde la Grecia Clásica la palabra “skhole”(ocio), significaba exención de toda actividad y la condición propicia para la contemplación, la reflexión e introspección, caminos necesarios para encontrar la felicidad,

${ }^{1}$ El término ocio será entendido como sinónimo de la palabra "lazer” (portugués), “leisure” (inglés) y "loisir” (francés) aspectos que serán tratados más detalladamente en el desarrollo del texto. 
mediante el desarrollo de los talentos humanos más elevados. En esta misma línea, siguiendo a De Grazia (1966), vemos que Aristóteles postuló que el ocio era un estado en el cual la actividad se lleva a cabo como un fin en sí mismo, a diferencia del trabajo y de las ocupaciones para la subsistencia, que solo serían un medio para alcanzar otros fines. Desde esta visión el ocio era comprendido como una de las formas privilegiadas para acceder a la felicidad, razón primera de la existencia humana.

Es así que investigar al ocio buscando su resignificación y considerando los vínculos que establece con todos los otros aspectos de la vida social y cultural, especialmente en lo relacionado con un aprendizaje transformacional, será un aporte significativo para la humanización de nuestras sociedades.

\section{Aclaraciones iniciales}

A pesar de la permanente necesidad de justificación del ocio como objeto relevante de investigaciones, esta situación comenzó a cambiar en los últimos años en varios países latinoamericanos. Algunas evidencias son el crecimiento de los grupos de estudios y de las investigaciones sobre la temática del ocio, los trabajos presentados en congresos científicos, simposios y seminarios, así como su inserción en programas de estudios de varios cursos, en diversos ámbitos y niveles² .

Es así que, el debate sobre el ocio, el tiempo libre y la recreación viene ampliándose y diversos autores, como Gomes y Melo (2003), apuntan algunos motivos para la difusión del tema en la actualidad, dentro de los cuales destacan el crecimiento de la llamada industria del entretenimiento, el incremento de las iniciativas gubernamentales (explicitas o no) relacionadas con el ocio y la recreación, así como los cuestionamientos acerca de la centralidad ocupada por el trabajo en nuestra realidad social, especialmente en los grandes centros urbanos.

\footnotetext{
${ }^{2}$ Actualmente en América Latina existen varias Maestrías vinculadas a la Recreación y Tiempo Libre: Maestría Profesional en Recreación - Universidad de Costa Rica; Maestría en Teorías y Políticas de la Recreación - de Universidad de Comahue, Argentina; Maestría en Recreación - Universidad YMCA, México; Maestría en Recreación y Tiempo Libre - Escuela Politécnica del Ejército, Ecuador; Maestría en “Lazer” - Universidade Federal de Minas Gerais, Brasil. A su vez existen varios cursos de Magíster y Doctorado en los llamados países desarrollados vinculados a estas temáticas. También en universidades latinoamericanas se imparten muchas cátedras que tratan sobre la recreación, el ocio y el tiempo libre, como parte de la formación profesional, principalmente en las carreras de educación física y turismo. En varios países, universidades y centros de formación técnica y profesional, como es el caso de Uruguay, México y Argentina, entre otros, hay cursos que forman técnicos en recreación y tiempo libre. Destacando que en general casi todos estos cursos hablaran de recreación y no propiamente de ocio, salvo contadas excepciones.
} 
Muchas veces al estar centrados en encontrar respuestas olvidamos que lo importante son las preguntas. Por lo cual empecé este estudio planteándome algunas preguntas claves, las cuales sirvieron de guía de esta investigación: ¿De qué manera el ocio es entendido en los estudios sistematizados sobre el tema y en el imaginario social latinoamericano? ¿Será que el ocio puede colaborar con la transformación social de nuestras sociedades, tornándolas más humanas y sustentables? ¿Cuál es el aporte que puede hacer el ocio en la construcción de nuevas realidades sociales?

Este estudio procura profundizar en estas y otras preguntas, sin llegar a responderlas por completo y entendiendo que el ocio resignificado, potencialmente, podrá ser un elemento importante a ser considerado al pensar en un aprendizaje transformacional que colabore con la evolución y el desarrollo humano y social.

Al constatar los alarmantes problemas sociales y ecológicos en los cuales está inmersa la humanidad y el planeta en su totalidad, se vuelve necesario repensar los modelos de creencias y los modelos paradigmáticos en los cuales están basadas las sociedades contemporáneas.

Desde esta nueva perspectiva, si se desea de forma cierta evolucionar como especie humana y construir sociedades realmente democráticas, participativas, equitativas, solidarias, respetuosas de los seres humanos y de la vida, deberemos realizar este profundo cambio paradigmático. Me pregunto ¿Cuáles son las contribuciones que un ocio revalorado, resignificado y contrahegemónico puede aportar en estos desafíos?

Como punto de partida, planteo que repensar y resignificar al ocio, en sus múltiples vínculos con los otros ámbitos de la vida en sociedad, será uno de los nuevos caminos desde los cuales poder empezar a "disoñar" (CALVO, 2007), esto es diseñar y soñar al mismo tiempo, con otro mundo posible y distintos.

\section{Algunas definiciones introductorias}

Diversos autores latinoamericanos (Suarez, 2009; Osorio, 2009; Ried, Leiva y Elizalde, 2009) apuntan a las dificultades conceptuales que rondan a la palabra recreación y términos similares, tales como animación sociocultural, tiempo libre e incluso ocio. Muchas veces esos términos son utilizados indistintamente, generando equívocos conceptuales, contradicciones y profundos problemas de comprensión. De igual forma, es posible constatar una pluralidad de sentidos y significados atribuidos a la palabra recreación en los países de América Latina, lo que compromete, en parte, el avance de los conocimientos sobre el tema.

Para evitar mayores equívocos, parto aclarando que el concepto de tiempo libre no equivale a recreación, ni a ocio. Generalmente, el tiempo libre es pensado como los momentos en los cuales la persona está fuera del 
trabajo, por lo cual se supondría que ella podría disfrutar de estos momentos de forma libre. Lo cierto es que tal como lo indican algunas investigaciones $^{3}$, el tiempo fuera del trabajo no equivale a un tiempo totalmente disponible para el ocio o la recreación. Existen otras obligaciones que cumplir además de las laborales remuneradas o de las que permiten obtención de ingresos económicos, entre las cuales se puede señalar: trabajo doméstico para el propio hogar; cuidado de niños y adultos que requieren apoyo, del propio hogar; apoyo a otros hogares; trabajo voluntario para la comunidad; dormir; comer; mantener higiene personal; trasladarse; participación política o religiosa; etc.

Como podemos constatar, estas actividades no son necesariamente optadas por quienes las realizan y a su vez no podrán ser catalogadas como vivencias de ocio o como activides de recreación. De este modo, disponer de tiempo libre no equivaldrá, directamente, a una vivencia de ocio, como a su vez participar en actividades recreativas tampoco significará, necesariamente, estar viviendo una experiencia de ocio. De aquí pregunto ¿Qué entendemos por recreación?

La palabra recreación, generalmente, es utilizada para designar a las actividades de diversión, entretención y esparcimiento. Es así que el Diccionario de la Real Academia Española define "recreación” como: “acción y efecto de recrear" y "diversión para alivio del trabajo". ${ }^{4}$ Casi siempre, salvo algunos avances muy específicos, la recreación ha estado asociada únicamente a actividades de esparcimiento, las cuales muchas veces carecen de mayor reflexión y consistencia teórica.

Lo predominante ha sido entender a la recreación casi exclusivamente como un activismo, mostrando una clara influencia del movimiento conocido como "recreacionismo" higienista, que tuvo sus orígenes en el fin del siglo XIX en Estados Unidos, como una forma de frenar el surgimiento males sociales (delincuencia, alcoholismo, libertinaje y otros vicios), pero a la vez como una forma de control social de ese nuevo tiempo libre, de descanso y de posible ociosidad, que tenía la masa trabajadora como consecuencia de la reducción de la jornada laboral.

Este modelo generó la sistematización de conocimientos y metodologías de intervención sobre la recreación, fomentó la creación de espacios propios para la práctica de actividades recreativas (como playgrounds, centros de recreación, plazas de deportes y jardines de recreo) y abrió nuevos campos de formación y actuación profesional. Con el apoyo de instituciones como la Asociación Cristiana de Jóvenes, YMCA,

\footnotetext{
${ }^{3}$ Valorización del Trabajo Doméstico No Remunerado: Encuesta de Uso del Tiempo. SERNAM. Este estudio, de propiedad de SERNAM, fue realizado el año 2007 en conjunto por el Instituto TRASSE de la Universidad Bolivariana y la Corporación DOMOS. No ha sido publicado.

${ }^{4}$ www.rae.es Acceso el 27 de agosto de 2009.
} 
el "recreacionismo” se propagó rápidamente por varios países, alcanzando especialmente a América Latina. (Gomes y Pinto, 2009)

En este proceso, fue ampliamente difundida la concepción de la recreación como sinónimo de actividades recreativas encargadas de llenar, racionalmente, el tiempo vago u ocioso de niños, jóvenes y adultos, con opciones consideradas saludables e útiles desde el ponto de vista higiénico, moral y social. Con esto, la recreación dirigida fue considerada esencial para la formación de valores, hábitos y actitudes a ser consolidados en las horas vagas, además de ser presentada como solución para los problemas de salud, para las dolencias crónicas, para favorecer la identidad comunitaria y cultural y, para la introducción de las artes plásticas y teatrales. (Butler, 1973)

En este mismo contexto, es necesario destacar que en los países de América Latina donde el español es la lengua oficial, generalmente, al referirse al objeto de estudio de esta investigación se habla de recreación y no de ocio. Para entender la profundidad de esto es imprescindible comprender que detrás de todo concepto, entendido como expresión de una forma de conocimiento, siempre existirá una motivación y un interés, no necesariamente explícito, por lo cual será necesario de develarlo desde lo implícito y en lo que lo subyace. Es así que, el conocimiento no es neutro, ni ingenuo y siempre estará motivado por determinados intereses.

Desde aquí surge la pregunta ¿Cuál será la razón de que se hable de recreación o tiempo libre y no de ocio? Creo que esto se debe a que la recreación representaba lo recomendable, y el ocio, en cambio, representaba lo prohibido y lo penalizado. Desde este punto de vista postulo que la recreación fue ideada, en la modernidad, como una herramienta para el mantenimiento del orden social, al ser tratada como un instrumento para la educación moral, con lo que se buscó higienizar y lograr así la profilaxis y eugenesia social. Desde esta perspectiva la recreación podría ser entendida como un dispositivo de control social del tiempo libre, esto es un dispositivo de control sociopolítico.

Ya en la actualidad y yendo más allá de los orígenes históricos de la recreación, destaco que ella, al igual que el ocio, no posee en si misma elementos positivos, ni negativos, y estos atributos estarán determinados, en especial para la recreación, dependiendo de la forma en la cual se aplican estas actividades específicas. Pudiendo así, la recreación al igual que el ocio, ser útil para la mantención de un orden social injusto e inhumano o, en cambio, posibilitar el desarrollo de una visión contrahegemónica y liberadora para el ser humano. (Gomes y Elizalde, 2009)

Avanzando en estas definiciones y buscando profundizar en otras perspectivas que ayuden a ampliar y encontrar conceptos que expresen de mejor forma lo esencial del objeto de estudio de esta investigación, el Diccionario de la Real Academia Española define “ocio” como un momento de “cesación del trabajo, inacción o total omisión de la actividad”, como el 
“tiempo libre de una persona”, para la “diversión u ocupación reposada, especialmente en obras de ingenio, porque estas se toman regularmente por descanso de otras tareas". ${ }^{5}$

Desde esta definición el ocio es entendido en oposición abierta al trabajo y como lo contrario de este, y a su vez como una forma de utilizar y llenar el llamado tiempo libre. Con lo cual, considero que se mostrará nuevamente una visión parcial y reducida en la comprensión del ocio.

En su origen en Grecia el ocio o "skhole" era fundamentalmente positivo. En esa época era entendido como el tiempo disponible y como la ausencia de la necesidad de estar ocupado, lo que permitía la contemplación filosófica, el desarrollo de las artes y de los talentos superiores (De Grazia, 1966). Un elemento importante de señalar es la necesidad de desmitificar la visión de ocio de Grecia, ya que ella suponía que este solo podría ser vivenciado por personas libres y pertenecientes a las elites de la sociedad, por lo tanto, posible solo para determinados segmentos privilegiados de la sociedad, lo que negó la existencia de todas las otras expresiones culturales de ocio del resto de la sociedad griega.

A su vez, si analizamos etimológicamente la palabra ocio, constatamos que esta proviene del término latín “otium”, el que estaba, en esa época, vinculado a la noción de descanso y reposo, de retiro, soledad y tranquilidad. Posteriormente en la Roma antigua, surge un concepto correlativo y opuesto al "otium" (ocio romano) el "negotium", que literalmente fue entendido como la negación del ocio, como el "no ocio" y que significaba básicamente "ocupación y quehacer”, del cual deriva la palabra negocio. (De Grazia, 1966)

Destaco que así el trabajo (negocio y comercio) fue entendido como la negación del ocio. Para tener una visión más clara sobre la forma de entender ocio y trabajo en la antigüedad señalo que etimológicamente la palabra trabajo deriva del término latino "tripalium", el que se refería a un instrumento de tortura para obligar a los esclavos (Racionero, 1983). Con todo esto se muestra que en la visión clásica (Grecia y Roma antiguas) el ocio era mucho más valorado que el trabajo, algo distinto a lo que ocurrió en la modernidad occidental, en el cual todo lo improductivo fue condenado y castigado, salvo si reportaba algún tipo de utilidad.

De este modo, ya en la modernidad, la forma de percibir al ocio fue marcada por una perspectiva negativa, lo que pudo haber surgido, en parte, producto de la influencia del protestantismo, al ver las vivencias de ocio como un vicio y la educación como un medio moralizante para el trabajo (Requixa, 1977). La visión protestante, inglesa y norteamericana, en cuanto ética del trabajo como bien supremo, rechazó al ocio por considerarlo

\footnotetext{
${ }^{5}$ www.raes.es Acceso el 27 de agosto de 2009.
} 
como una potencial amenaza para el “espíritu” de base del modelo de producción capitalista. De este modo, el sentido griego original de ocio como una manifestación cultural basada en la meditación, la reflexión y la sabiduría fue vaciado de su esencia original, y así, desvalorizado y llenado de prejuicios. (Gomes, 2008)

Es cierto que en América Latina el protestantismo no fue la principal religión en ese período histórico, pero sin duda alguna la influencia norteamericana, desde los Estados Unidos, fue y es muy fuerte a nivel social en la visión de mundo y concepciones económicas, políticas, educativas y culturales en Latinoamérica. Llegando a ser, el “imperio del norte”, un modelo de sociedad al que debíamos de acceder, para así cumplir con el anhelado (falaz) sueño de ser un país desarrollado. Por esta vía se logró imponer un modelo de sociedad capitalista y un ideal de estilo de vida (forma de producción y consumo), lo cual abarcó a todas las expresiones culturales y sociales, incluyendo al ocio.

Ya en la actualidad, según Cuenca (2008), la concepción de ocio adquiere cada día una visión más positiva, ya no siendo identificado solo con el descanso, los feriados, y la diversión, ampliando su significación al ser considerado como una experiencia humana necesaria, capaz de proporcionar autorrealización, como un derecho y un elemento que aporta a la calidad de vida. Desde esta perspectiva, el ocio es vivido por las personas que poseen estilos de vida más avanzados, ya que este radica en una mudanza de mentalidad y en una concepción diferente y más evolucionada de la vida y del mundo.

Ampliando esta reflexión, y como lo señalamos en otro texto (Gomes y Elizalde, 2009) en el idioma portugués el término más utilizado al hablar de ocio es la palabra "lazer", el cual también existe al hablar de "leisure" en inglés y "loisir" en francés, todos términos que tienen un significado similar. Las palabras “lazer, leisure y loisir" tienen un origen etimológico común al venir del término latín licere, que significa: "ser permitido, poder, tener derecho”.

Por lo anterior, en este estudio utilizo la palabra “ocio” como sinónimo de las palabras lazer, loisir y leisure, al igual que Rhoden, quién señala que: "muchos autores utilizan las expresiones diversión, juego, recreación, distracción, entretenimiento, tiempo libre, como si fuesen lo mismo”... que ocio... "aunque, al profundizar en el estudio de estos términos, percibimos que no lo son.” (2008, p. 58) La autora entiende al ocio como una experiencia personal "permitida” y "que permite”, sea el descanso, el disfrute o el desarrollo humano. Creo que ella destaca estos elementos de permisión probablemente basándose en el significado etimológico del término latino licere.

Yendo más allá de lo señalado por Rhoden, el ocio puede a su vez llegar a generar una experiencia de apertura marcada por una actitud que rompa y transgreda con lo permitido y con lo lícito, mostrándose muchas 
veces al borde de lo socialmente adecuado y aceptado. Justamente a esto se debe uno de los grandes temores, así como peligros que representa el ocio para el mantenimiento del "status quo". De aquí surge, en parte, el intento de acallar y prohibir la disruptividad, contracorriente, alteridad e innovación subversiva, y todo aquello que pueden expresar un ocio creativo, caótico y transformacional. No está demás decir que los "locos" (en el sentido de ser quienes se atreven a tener otras miradas sobre el mundo y la realidad) y los revolucionarios siempre han estado fuera del orden establecido, siendo excluidos, encarcelados o castigados, ya que en muchos casos son ellos los que originan algunos de los significativos cambios culturales y sociales vividos por toda sociedad. Con esto agrego que el ocio a su vez puede permitir el desarrollo de una nueva identidad y de un sentido de pertenencia más abarcador, posibilitando la generación de una sensación de libertad.

Por lo anterior aclaro que paralelamente, así como el término "licere" genera todas estas reflexiones, el concepto latino "otium" puede abrir otras perspectivas para la conceptualización y comprensión del fenómeno del ocio.

Tal parece que necesitaremos desarrollar definiciones y comprensiones más profundas y elaboradas de lo que entendemos por estos conceptos, evitando caer en los equívocos conceptuales, contradicciones y problemas de comprensión mencionados.

\section{Problematizando y profundizando los significados del ocio en la actualidad}

Una de las vertientes desde donde se piensa nuestro objeto de estudio es a través de la llamada "sociología del ocio". Desde esta perspectiva lo común es entender al ocio en clara oposición al trabajo, definiéndolo como un tiempo libre de obligaciones, ya sean laborales, profesionales, sociales, familiares, políticas y otras actividades sentidas y vivenciadas como obligatorias y no optadas de forma voluntaria por quién las realiza, como postula Dumazedier. (1973)

A su vez, este mismo autor (1979) propone ciertas características específicas y constituyentes del ocio:

a) Carácter hedonista: el ocio es marcado por la búsqueda de un estado de satisfacción. “Eso me interesa”. Esa búsqueda por el placer, la felicidad, la alegría es de naturaleza hedonista y representa la condición primera del ocio.

b) Carácter desinteresado: el ocio no está, fundamentalmente, sometido a fin alguno sea lucrativo, profesional, utilitario, ideológico, material, social, político, socio-espiritual. 
c) Carácter personal: las funciones del ocio (descanso, diversión y desarrollo de la personalidad) responden a las necesidades del individuo, considerando las obligaciones primarias impuestas por la sociedad.

d) Carácter liberador: el ocio es liberación de obligaciones (institucionales, profesionales, familiares, socio-espirituales y socio-políticas) y el resultado de una libre elección.

Fundamentado en las reflexiones plantadas por Gomes (2007), considero adecuado preguntar si las características propuestas por Dumazedier pueden tomarse como ciertas o solo como simples indagaciones. Tal parece que, con excepción del aspecto hedonista, relacionado con la búsqueda de algún tipo de satisfacción, las demás características evocan solo indagaciones, ya que ¿Hasta que punto será posible este total desinterés? ¿Será que el ocio es un fenómeno neutro y, por lo tanto, aislado de nuestra vida social? ¿Será cierto que el tiempo de ocio está exclusivamente determinado por las necesidades individuales? ¿Podrá ser posible vivir el tiempo de ocio como el término o liberación de todas las demás obligaciones?

Al formular estas preguntas postulo la necesidad de repensar las características formuladas por Dumazedier, quién más específicamente plantea que el ocio puede ser comprendido como:

"un conjunto de ocupaciones a las que el individuo se puede entregar voluntariamente, sea para reposar, para divertirse, para recrearse y entretenerse, o además, para desarrollar su formación desinteresada, su participación social voluntaria, o su libre capacidad creadora, después de liberarse o desembarcarse de las obligaciones profesionales, familiares y sociales.” (Dumazedier, 1973: 34)

Nuevamente esa concepción puede ser cuestionada por entender al ocio como "un conjunto de ocupaciones”, ya que además de restringirlo a la práctica de determinadas actividades, a su vez, supone que el individuo debe estar ocupado, por lo cual en esta definición quedaría excluido todo lo vinculado a algunas formas de ocio, en cuanto momento contemplativo, meditativo o de introspección, que pudiese ser percibido como hacer nada.

Como señalo, Dumazedier sitúa al ocio en clara oposición a todas las otras necesidades y obligaciones de la vida cotidiana, especialmente las del trabajo ¿Y que pasa si en el trabajo, por ejemplo, se generan momentos y espacio de ocio, incorporando una sensación placentera de estar en un tiempo optado? Tal parece que las fronteras de los tiempos y espacios sociales y culturales no son necesariamente rígidos, ni tan claros y absolutos, como se pretende hacer creer.

Basado en lo anterior, considero imprescindible abrirnos a entender que trabajo y ocio "no constituyen polos opuestos, sino más bien representan lados distintos de una misma moneda”... ya que “en la vida cotidiana, no siempre existen fronteras absolutas entre trabajo y ocio, tampoco entre 
ocio y las obligaciones profesionales, familiares, sociales, políticas, religiosas. Por tanto, no vivimos en una sociedad compuesta por dimensiones neutras, estanques y desconectadas unas de otras”. (Gomes, 2004: 121)

Continuando en este intento de profundizar en la comprensión del ocio, destaco otros aportes como los de Gaelzer (1979), quién llegó a la conclusión que la mayoría de los autores admiten la existencia de tres elementos claves, los cuales son: tiempo, actitud y actividad (ocupación), manteniéndose vigente la influencia de Dumazedier en estos postulados. Para la autora, estos tres elementos son interdependientes, ya que separadamente, no cumplen con las condiciones necesarias para la existencia de ocio.

Por su parte Bramante (1998) plantea que lo lúdico es el eje principal, del ocio, algo que comparten la mayoría de los autores por él estudiados. De acuerdo con su visión, el ocio está constituido por tres elementos: tiempo, espacio y actitud. Aclaro, desde mi perspectiva, que lo lúdico ${ }^{6}$ en cuanto eje principal y elemento transversal del ocio no se restringe exclusivamente a los juegos, entretenciones o diversiones, y va más allá de estos, refiriéndose a una gama mucho más amplia de expresiones culturales caracterizadas principalmente por una “actitud” personal de disfrute, más que por algún tipo de actividad específica. Lo lúdico es un elemento mucho más amplio que el ocio, no limitándose a este.

Siguiendo estas reflexiones, lo que diferencia al ocio de otras prácticas sociales y culturales, en nuestra sociedad, es el hecho de que los elementos que lo caracterizan son:

a) un tiempo vivido en el momento presente, y que no se limita solo a los períodos institucionalizados, como los fines de semana o las vacaciones;

b) un espacio/lugar del cual los sujetos se apropian, en el sentido de transformarlo en punto de encuentro... consigo mismo, con otros, con el mundo... y de convivencia social;

c) manifestaciones culturales con actividades o contenidos

\footnotetext{
${ }^{6}$ Aparte de la multiplicidad de definiciones, lo lúdico representa una posibilidad de expresión humana de significados de la/en la cultura. Es así un lenguaje, referido a jugar consigo, con otro y con el contexto, que puede manifestarse de varias formas (oral, escrita, gestual, visual, artística, etc.), pudiendo acontecer en todos los momentos de la vida (trabajo, educación, ciencia, política, ocio, etc.). Las prácticas culturales no son lúdicas en sí mismas, porque es la interacción de la persona con la experiencia vivida lo que posibilita la ocurrencia de la ludicidad. Lo lúdico constituye nuevas formas de disfrutar y participar de la vida social, marcadas por la exaltación de los sentidos y de las emociones - mezclando alegría y angustia, relajamiento y tensión, placer y conflicto, libertad y concesión, etc. Presupone la valorización del proceso vivido y no solamente del resultado alcanzado (Gomes, 2004).
} 
vivenciados como disfrute y goce de la cultura, sea como posibilidad de diversión, de descanso o de desarrollo;

d) una actitud fundamentada en lo lúdico... entendido como expresión humana de significados de la / en la cultura vinculados al jugar, bromear y tener buen humor, consigo mismo, con los otros y con la realidad. (Gomes, 2004, 2007: 30-31)

Todos estos elementos están enraizados en lo lúdico y no tienen carácter de obligatorios, y no son vistos como un conjunto de tareas a ser cumplidas, por lo cual los sujetos participan y se involucran de forma voluntaria.

A modo de síntesis, entendemos que el ocio es una de las múltiples dimensiones de la cultura, así como también lo son el trabajo, la educación, la familia, entre otras. Continuando en esta línea argumentativa comprendo que:

"el ocio es constituido conforme a las peculiaridades del contexto histórico y social en el cual se desenvuelve e implica una "producción cultural” - en el sentido de reproducción, reconstrucción y transformación de diversos contenidos culturales vivenciados por las personas, grupos e instituciones. Estas acciones son construidas en un tiempo/espacio de producción humana, dialogan y sufren influencias de las demás esferas de la vida en sociedad, y nos permiten resignificar continuamente la cultura.” (Gomes, 2007: 30)

En América Latina producto de la diversidad cultural y humana que la componen, el ocio no será un fenómeno homogéneo y estático, mostrando variadas formas y expresiones propias ¿Como será vivenciado y entendido en el imaginario social latinoamericano el ocio?

\section{Ocio en las sociedades latinoamericanas: relectura del imaginario social actual}

Hablar de sociedad latinoamericana es una suma de realidades amplias, diversas y heterogéneas, llenas de contrastes, ambivalencias y contradicciones que necesariamente deberán ser entendidas en plural. Por lo cual hablaré de "sociedades latinoamericanas" al postular que no existe una única sociedad latinoamericana. Ya sea desde las propias realidades territoriales y locales específicas, entiéndase por países, regiones, comunas, barrios, etc., como dentro de ellas mismas, sabemos de la existencia de variadas culturas conviviendo paralelamente dentro de una mismo territorio.

Culturas singulares y plurales que presentarán características específicas dependiendo de variables tales como factores de identidad, histo- 
rias, mitos, fantasías y sueños, los contextos políticos, económicos, sociales, en los cuales se esté inmerso, entre otros elementos. A su vez estas realidades culturales estarán determinadas en gran medida por factores etarios, raciales, étnicos, de género, educacionales y tantas otras características específicas de los miembros específicos de esos grupos humanos. Desde esta perspectiva planteo la presencia de la multiculturalidad y de la interculturalidad en América Latina, y al igual que Marina (2002), los entiendo como fenómenos actuales, más allá de la tendencia global a la asimilación y homogenización cultural.

Es así que hablar de la existencia de una realidad única de cualquier fenómeno o factor de una cultura, como algo absoluto en una sociedad, será siempre una generalización, la cual estará lejana de expresar estas múltiples dimensiones y diversas realidades humanas simultáneas que coexisten, se entrelazan, influyen, interafectan e interrelacionan en una dinámica de conservación y trasformación constante. Elaboro esta explicación para evitar presentar una visión estática y rígida, que no considere las diferencias y, a su vez, similitudes existentes en las realidades multiculturales e interculturales latinoamericanas.

Basados en lo anterior, planteo que en las sociedades latinoamericanas el ocio no presenta una forma única de ser vivenciado y entendido, lo que no quita que al mismo tiempo paradojal y paralelamente, presente tendencias similares en como es vivido y comprendido desde un imaginario socialmente construido.

Siguiendo las reflexiones iniciales de Ziperovich y Chervin (2005), y como ya fue señalado, en Latino América habitualmente el ocio es subvalorado y entendido en el lenguaje popular como sinónimo de "vago". A su vez se ve al ocio como sinónimo de inacción, holgazanería, y como el vicio de no trabajar y de perder el tiempo. Así encontramos el tradicional refrán popular que dice: "el ocio es la madre de todos los vicios”.

Conocida es la idea de que los juegos son solo para los niños y las cosas verdaderamente "serias" e importantes del mundo son para los adultos. De aquí, quizá, el que todo el sistema educativo esté centrado en educar a los niños, futuros adultos del mañana, para el mundo del trabajo, y no para un desarrollo integral que considere la necesidad de ocio. Perdiendo así tanto el ocio, como la recreación, su potencial en cuanto herramienta educativa y pedagógica como elementos que colaboren con la evolución y transformación social.

A lo anterior se agrega que al quedar el ocio en manos del mercado, como ocurre en muchos casos en nuestras realidades latinoamericanas, este será comprendido casi exclusivamente como un nicho económico generador de lucro e interpretado así como un bien o servicio para los clientesconsumidores. De esta forma, el ocio, será entendido únicamente como otro objeto de consumo, perdiendo así su potencial capacidad de ser un aporte en la generación de otras perspectivas creativas y críticas, que per- 
mitan cambiar la mirada y hacer frente a las problemáticas sociales actuales de forma innovadora y renovada. Por esta vía, la relación que la ciudadanía establecerá con su propio ocio será pasiva, generando un consumo alienado, marcado por una fuerte tendencia escapista y sobreconsumidora.

Añadido a todo esto, los medios de comunicación masivos entregan la visión del ocio como un ideal a ser alcanzado, en el cual la imagen del millonario, eterno adolescente, que descansa sin tener que trabajar ni un día, será casi un sueño no necesariamente reconocido, pero si anhelado de forma silenciosa por la gran mayoría. De esta forma vemos como el ocio ocupa un lugar central en este nuevo ideal en el imaginario social, en el cual la aversión y rechazo al trabajo serán un elemento nuevo, central y paradojal, que muestra las profundas contradicciones existentes en nuestras sociedades actuales.

Podemos ver así la coexistencia de fuerzas antagónicas y ambivalentes, las que por un lado según el modelo social de crecimiento continuo de la economía, desde una moral productivista capitalista, rechazará al ocio por considerarlo contrario a los ideales de la sociedad moderna, donde la idea de progreso, en cuanto crecimiento de la producción y el consumo, será el objetivo primero de la vida en sociedad. Pero a su vez, contradictoriamente y de forma paralela, se buscará un ideal hedonista, en el cual la despreocupación, el descuido y el descanso continuo, con dinero, serán el sueño a alcanzar, pero solo concretados por unos pocos privilegiados. Así la ecuación puede ser “trabajar poco y ganar mucho dinero”, para disfrutar de los placeres de la vida, entre los cuales el ocio será una de las metas supremas. De esta forma, cambia sólo en apariencia la lógica capitalista ya que entramos a resaltar un aspecto medular del modelo, en este caso el consumismo. Con esto la alienación humana ya no entra sólo por la vía del trabajo, sino también, por el consumo, a través del ocio, que se transforma en una nueva forma de adicción al buscar, como ideal, poseer la mayor cantidad de bienes y servicios - entiéndase hiperconsumo - algo que definitivamente no será posible para todos, al vivir en un mundo finito y limitado en sus recursos ambientales (Elizalde, 2008a).

Con lo anterior postulo que al ser nuestras sociedades contradictorias, llenas de tensiones y al estar en constante e impredecible cambio, está emergiendo un nuevo sujeto social y un nuevo imaginario social que expresa como ideología base el sobreconsumo, lo desechable, lo fragmentado e individual, material y concreto, pero a su vez lo efímero, fugaz e inmediato. Todas estas novedosas características harán vivir de forma distinta el ocio a este emergente sujeto social en las agitadas sociedades actuales.

Lo que se contrasta con realidades sociales aún existentes en la vida de muchas comunidades locales en las cuales la solidaridad, la empatía y la valoración de los otros, en cuanto legítimos otros, sigue siendo un elemento relevante y significativo.

Entonces ¿Habrá sido similar la vivenciar el ocio en todos los tiem- 
pos y contextos históricos? ¿Cómo habrá sido vivido en las culturas africanas, orientales, indígenas americanas y otras no occidentales? ¿El ocio siempre existió o representa un fenómeno característico de las modernas sociedades urbano industriales?

\section{Ocio y humanización}

No ha sido fácil el reconocer lo universal de la declaración de los derechos humanos, que en muchos casos es solo un ideal y no necesariamente una realidad vivida por nuestros pueblos. Son varios siglos de opresiones, exclusiones e injusticias de variadas formas. Basta solo recordar que hace menos de 150 años aún existía esclavitud en algunas partes del planeta, y si somos un poco más rigurosos podremos reconocer que aún existe esclavitud, aunque esta sea ilegal o esté escondida. Lo concreto es que nuestras sociedades así como presentan grandes avances en aspectos tecnológicos y científicos, paradojalmente presentan a su vez significativos atrasos en aspectos éticos y morales. (Elizalde, 2008)

De igual modo, el hablar de avances en el campo de las prácticas del ocio y la recreación, o de mayores condiciones para vivenciar un tiempo libre de forma integral, se transforma en bellas palabras pero que no se condicen con la realidad de amplios sectores de la población, excluidos de poder satisfacer sus necesidades humanas fundamentales, siendo el ocio una de estas necesidades.

Sumado a lo anterior se agrega las actuales prácticas de sobreconsumo como modelo social, homogeneizante, en la forma de vivenciar el ocio, con lo cual, considero que justamente se requiere que este sea un tiempo-espacio caracterizado por una actitud crítica, creativa y realmente liberadora, la cual colabore con la transformación social en el camino de construir sociedades más solidarias, justas y sustentables.

Añadido a lo anterior, se pretende hacer creer que cada vez se avanza más en las condiciones óptimas para el aumento de los tiempos de ocio, producto de una disminución de la duración de la jornada laboral. Frente a esto, postulo que lo que está creciendo, para la amplia masa de trabajadores, es la precarización laboral, traduciéndose esto en un deterioro de las condiciones de trabajo y de vida en general. De esta forma, pongo en duda la tan habitual afirmación que habla de un aumento en la disponibilidad de tiempo libre, al preguntar ¿Será cierto que se trabaja cada vez menos tiempo? Si esto fuera cierto ¿Significa que la carga laboral es menor? Y a su vez, en términos de uso del tiempo ¿Significa que existe cada vez más tiempo destinado al ocio? Y si así fuese ¿Qué tipo de ocio está emergiendo en nuestras sociedades actuales?

Creo que estas y muchas otras preguntas podrán alertarnos de que así como se requiere un urgente cambio de paradigma a nivel ambiental y ecológico, para acceder realmente a sociedades sustentables, de igual for- 
ma se requieren de profundos cambios paradigmáticos a nivel epistemológico, educativo, político, social, laboral y económico. Requerimos de profundas transformaciones que posibiliten el enfrentar los variados conflictos, contradicciones, tensiones y problemáticas producto de seguir anclados en un modelo adicto al crecimiento económico, a la productividad y de esta forma también adicto de forma ciega al hiperconsumo. Todos elementos estructurales y fundantes del modelo hegemónico de sociedad actual.

En todo esto el ocio sin duda es afectado, en la forma de ser vivido, entendido y soñado a nivel social e individual, con efectos impredecibles e impensados para el futuro de nuestras sociedades humanas, lo que resalta la importancia de resignificarlo en cuanto elemento integrante de una educación comprometida con un aprendizaje transformacional personal y colectivo.

\section{Resignificación y valoración del ocio: Desafíos de un aprendizaje transformacional}

El estado actual de la ciencia, casi como un espejo de lo que son nuestras sociedades y culturas, nos indica que a nivel global, como postula Morin (1988), estamos transitando desde una época de certezas a un tiempo de crecientes incertezas e incertidumbres, en que ya no existen conocimientos ni verdades absolutas.

A nivel social avanzamos casi como un barco sin rumbo claro, transformando nuestra casa planetaria y nuestra civilización, en un verdadero Titanic pronto a caer en el abismo. Por lo cual en esta época de pérdida de utopías y fin de los modelos confiables, reelaborar, crear y recrear nuestros sueños y anhelos comunes, casi como buscando encontrar luceros que orienten nuestro transitar en esta noche de la transformación, es una necesidad urgente de empezar a construir.

Lo primero, al considero que el ocio al ser un tiempo/espacio optado y libremente elegido, puede representar una de las múltiples alternativas que se requieren para transitar desde lo viejo a eso nuevo, emergente y desconocido que precisamos.

Postulo que el ocio puede representar tanto un espacio de libertad y dignificación de la condición humana, como contrariamente expresar una forma de reforzar las injusticias, alienaciones y opresiones sociales del presente (Gomes y Elizalde, 2009). Esta consideración resalta la necesidad de promover una educación crítica/creativa por y para el ocio, considerándolo en su doble aspecto educativo, o sea, como un vehículo y, a la vez, como un objeto de educación (Parker, 1978; Dumazedier, 1980; Marcellino, 1987), una vez que este representa una posibilidad de reflexionar sobre la sociedad en que vivimos. 
Es así, que en un intento por conocer el estado actual de nuestras sociedades, surge la pregunta ¿Qué pueden expresar de nuestras sociedades las diversas formas de vivir el ocio? Considero que la forma en que se vive el ocio podrá darnos pistas sobre los tipos de sociedades actuales.

Desde aquí, planteo que un ocio resignificado, en cuanto medio y fin, podrá colaborar, significativamente, con la transformación social, en el sentido de potencialmente tener la capacidad de ser una forma de expresión de las tensiones y contradicciones existentes en una sociedad.

Al posibilitar una visión crítica de la realidad social y una perspectiva nueva frente al estilo de vida actual, se estará abriendo un potencial de transformación frente al modelo social vigente. Esto es vivenciando al ocio con una actitud contrahegemónica frente al modelo social y cultural actual, el cual se presenta excluyente para amplios sectores de la población.

Es así que el ocio es un campo a través del cual podemos reflexionar sobre la sociedad con sus grupos, sus formas de organización temporal/ espacial, sus estilos de sociabilidad y sus variados conflictos. Siendo un soporte de múltiples significados, puede ofrecer una vía de acceso al conocimiento de los límites y de las posibilidades que se abren en nuestra realidad (Magnani, 2000). En síntesis, el ocio es un fenómeno que, a partir de sus peculiaridades, también nos permite pensar sobre nuestra sociedad y reflexionar sobre cuestiones más amplias, pues está estrechamente vinculado a los demás planos de la vida social.

En este ámbito, el ocio puede ser reconocido como un principio de construcción de ciudadanía - planetaria y no excluyente - de base en la implementación de acciones comprometidas con la inclusión y participación social.

Después de este recorrido que he realizado al analizar diversas perspectivas desde donde pensar y problematizar al ocio en la actualidad, busco hacer una primera propuesta que incluya el repensar todo esto, atreviéndome a encontrar senderos nuevos por los cuales transitar, pero a la vez darme la libertad de dejar dudas, incertezas y preguntas abiertas.

Por todo lo anterior postulo la urgente necesidad de encontrar nuevos referentes teóricos y prácticos que posibiliten hacer frente a todas las patologías ecológico-ambientales, sociales e individuales emergentes en nuestras sociedades contemporáneas.

Es así que me pregunto en relación al ocio resignificado y contrahegemónico ¿Cuál es el potencial transformacional que pudiese tener? ¿Cuáles serán los elementos radicalmente diferentes a las formas anteriores de comprenderlo y vivirlo? ¿Qué involucra el entender al ocio como una necesidad humana fundamental y como sería vivenciarlo desde satisfactores sinérgicos? ¿Qué relaciones son necesarias de establecer entre ocio y aprendizaje transformacional en las esferas de la educación y el trabajo? 
Será necesario de aclarar que el ocio no deberá ser entendido desde una visión mesiánica, en el sentido de ser pensado como un elemento que solucionará todos los problemas sociales actuales. Lo que no quita que si podrá ser planteado como uno de los muchos elementos que en conjunto con otros, al ser vivenciado de forma distinta, posibilitará, en parte, las necesarias mudanzas que el presente de la humanidad requiere.

Buscando una nueva forma de vivenciarlo es imprescindible reflexionar críticamente sobre, por ejemplo, su uso como posibilidad de evasión de la realidad, válvula de escape, quiebre de la rutina y fuga de los problemas, mediante un ocio alienado y exclusivamente consumista, el que claramente será contrario a lo que postulo en cuanto actitud y vivencia contrahegemónica. Por lo cual, basados en la Teoría del Desarrollo a Escala Humana (1986), será muy importante estudiar los posibles tipos satisfactores de la necesidad de ocio, en especial aquellos que podríamos entender como inadecuados, tales como los satisfactores destructores o violadores, inhibidores y pseudos-satisfactores.

A su vez, al entender y vivenciar el ocio como necesidad humana fundamental y ser satisfecho de modo sinérgico ${ }^{7}$, se podrá experimentar a una nueva forma de vivir el tiempo, como algo propio, más libre y conquistado. Lo cual puede parecer muy simple y sin mayor importancia, pero si constatamos que tiempo y espacio son dos de las categorías humanas existenciales básicas, por esta vía se podría estar dando un salto profundamente significativo en el sentido de dotar de libertad y capacidad de decisión, y así potencialmente de desarrollo de conciencia ética y autonomía a cada ser humano.

Desde esta perspectiva, el encontrar satisfactores sinérgicos para la necesidad humana fundamental de ocio, abrirá la posibilidad de comprenderlo y vivirlo de forma nueva, abarcando otras dimensiones de lo humano, ya que los satisfactores sinérgicos son aquellos que por la forma en que satisfacen una necesidad determinada, a su vez estimulan y contribuyen a la satisfacción simultánea de otras necesidades. Destaco que el principal atributo de los satisfactores sinérgicos es el de ser contrahegemónicos en el sentido de que revierten racionalidades dominantes tales como las de competencia y coacción (Max-Neef, Elizalde y Hopenhayn, 1986).

Un ejemplo clásico, de satisfactor sinérgico, será la lactancia materna (en su tiempo adecuado) que satisface la necesidad de Subsistencia, pero

\footnotetext{
${ }^{7}$ Sinergia significa el comportamiento de un sistema completo, que resulta impredecible a partir del comportamiento de cualquiera de sus partes tomadas aisladamente. Fueron los químicos en reconocer la sinergia, cuando descubrieron que toda vez que aislaban un elemento complejo, o separaban átomos o moléculas de un compuesto, las partes separadas y sus comportamientos singulares jamás lograban explicar el comportamiento de todas las partes asociadas. En este sentido, la sinergia connota una forma de potenciación, es decir, un proceso en que la potencia de los elementos asociados es mayor que la potencia sumada de los elementos tomados aisladamente. (Max-Neef, Elizalde y Hopenhayn, 1986: 45).
} 
a la vez estimula la satisfacción de las necesidades de Protección, Afecto, Identidad. Otro ejemplo, en el ámbito social, son las organizaciones comunitarias democráticas las que satisfacen la necesidad de Participación, pero a la vez estimula la satisfacción de las necesidades de Protección, Afecto, Creación, Identidad, libertad e incluso de Ocio. Otro ejemplo, será la meditación, la que satisface la necesidad de Entendimiento, pero a la vez estimula la satisfacción de las necesidades de Identidad, Creación y Ocio. La televisión cultural que satisface la necesidad de Ocio, y a la vez estimula la satisfacción de las necesidades de Entendimiento e incluso las necesidades de Identidad y Participación.

Es así que el revalorar y resignificar al ocio en cuanto necesidad humana fundamental satisfecha de forma sinérgica posibilitará, a su vez, por ejemplo, que se enriquezcan de sentidos los espacios educativos y el mundo del trabajo, abriendo la posibilidad de preguntar ¿Cómo sería incorporar ocio en las formas de entender la vida laboral? ¿Cómo sería romper con el antagonismo existente entre trabajo y ocio, entre deber y placer? ¿Qué ocurriría al llenar de ludicidad y al incorporar ocio y recreación en la educación formal ? Con todo esto intento poner en cuestión la profunda pregunta del porque se hacen las cosas ¿Cuál es el sentido primero de estudiar? ¿Cuál es el sentido profundo de trabajar?

Como ya esbocé, trabajo y ocio pudiendo ser categorías opuestas y antagónicas, a su vez ambos fenómenos pueden formar parte de una realidad compleja mayor, por lo cual desde una perspectiva dialógica, serían a la vez complementarios y no excluyentes. Está forma de comprenderlos incorpora la idea de un trabajo vinculado al ocio, esto posibilita concebir un trabajo vivido desde el ocio, conectado con el ocio, y ya no como categorías opuestas y antagónicas. A primera vista esto puede parecer contradictorio e imposible de ser logrado, pero si se indaga en esta revolucionaria propuesta, estaremos más cerca de un trabajo de calidad, entiendo que este será optado, esto es libremente elegido, y que a su vez llenará de realización personal y satisfacción a quién lo realiza, todos estos elementos propios de las vivencias de ocio.

Plantear la relación trabajo-ocio desde una nueva lógica, quizá no podrá ser, en la actualidad, una realidad vivida de forma absoluta y completa por toda la masa trabajadora, pero si puede significar una tendencia hacia la cual avanzar, en el sentido de hacer que el disfrute y la satisfacción personal, empiecen a ser parte de toda actividad laboral. Con el entendido que esto será buscando, explícitamente, la humanización del trabajo, el que se presenta hoy, en muchos casos, como alienado y alienante.

Esta nueva relación también podría ser vivida en los procesos de enseñanza-aprendizaje, pesando en un aula que motive a los alumnos y que despierte el interés de ellos al mostrar el sentido del conocimiento y los múltiples significados que pueden construirse a partir de él. Incorporando a su vez, lo lúdico, lo libremente elegido y el disfrute, en la búsqueda del desarrollo y realización personal, llenando de sentidos profundos a los par- 
ticipantes, es un desafío para una educación basada en un aprendizaje transformacional con énfasis en la trasformación y evolución social e individual.

Sabemos que sociedades alienadas y carentes de sentidos que den trascendencia a nuestros actos, son mundos muertos e inhumanos. Desde esta nueva perspectiva, el ocio resignificado puede ser uno de los elementos innovadores que coayuden a preguntarnos el porque y para qué de lo que hacemos, colaborando en la construcción de nuevas utopías sociales, elemento determinante para la evolución de las sociedades humanas y de los individuos que en ellas viven.

Por lo anterior, un ocio resignificado podrá aportar en la superación de los variados prejuicios que existen frente a todo lo considerado no productivo y desinteresado, todo lo que esté teñido de gratuidad y voluntariado, posibilitando el quitarle al ocio esta carga negativa que porta hasta nuestros días. Entendido así el ocio transmitirá nuevos significados, entre los cuales superar la dicotomía entre deber y placer, trabajo y disfrute, estudio y ludicidad, serán parte de estos impostergables desafíos. A la vez al ser entendido como derecho y como necesidad, permitirá, potencialmente, el surgimiento de un percepción de la realidad crítica, creativa y alternativa. Dando de esta forma la posibilidad de generar nuevas perspectivas desde donde entendernos y vivirnos en el mundo.

Un ocio contrahegemónico podrá ayudar a mudar muchos de los antivalores imperantes en la actualidad, tales como: el individualismo, la fragmentación social, el hedonismo exacerbado y auto-referido, la apatía, el desinterés por los otros, la falta de solidaridad y la ausencia de pensamiento crítico. A la vez un ocio contrahegemónico podrá ayudar a encontrar soluciones innovadoras para enfrentar el hiperconsumo, alienación y perdida de sentido e identidad, enajenación y despersonalización, así como la baja autoestima y subvaloración de si mismo, desprecio del propio contexto social local y perdida de un sentido existencial más trascendente.

Más allá que el ocio resignificado, contrahegemónico, y satisfecho sinérgicamnente, definitivamente, no será la solución a todas las problemáticas sociales actuales, en conjunto con otros elementos, puede ser uno de los fenómenos que co-ayuden en el necesario cambio de cosmovisiones y paradigmas, en la búsqueda de alternativas desde donde avanzar en la construcción de nuevos mundos posibles.

Mi propuesta es que justamente la resignificación del ocio y el vivirlo de forma contrahegemónica, buscando su satisfacción de forma sinérgica, abrirá la posibilidad de cuestionar el modelo vigente generando nuevas prácticas sociales e individuales, para lo cual un aprendizaje transformacional será decisivo y esencial en este procesos de necesarias mudanzas que el presente requiere.

Sin pretender encontrar respuestas a todas las profundas preguntas 
planteadas en este texto y dejándolas, por ahora, intencionalmente abiertas, planteo que este nuevo ocio nos puede mostrar algunas luces para salir de esta noche de desesperanzas, inercia y apatía en que, en gran medida, se ha convertido nuestro presente como humanidad.

Por lo cual, postulo que potencialmente el ocio desde una visión resignificada, revalorada y contrahegemónica (Elizalde, 2009) aportará en la transformación social ya que:

1- Es un campo de producción de nuevos conocimientos, individuales y colectivos.

2- Da la posibilidad de una nueva forma disfrute del tiempo, ampliando la capacidad humana de elegir sobre lo que nos afecta y de soñar con mundos distintos.

3- Da la posibilidad de pensar en una vida diferente (individual y colectiva), llena de sentido, abriéndose a la alteridad y al cambio.

4- Brinda una nueva forma de acceso a una mayor calidad de vida.

5- Entrega la posibilidad de repensar críticamente las sociedades actuales y el lugar de los seres humanos dentro de ellas.

6- Es un tiempo y espacio para la rehumanización de la vida individual y colectiva.

7- Otorga una apertura a lo creativo, a la búsqueda de la libertad y a la creación de identidad. y el trabajo.

8- Abre potencialmente una nueva forma de vivenciar la educación

9- Posibilita un tiempo y espacio para encontrase con uno mismo y con los otros, aceptándose.

A modo de cierre, creo útil recordar que una sociedad sin sueños es como un desierto donde la vida ya no florece, y todo se seca y muere. Los seres humanos requerimos para nuestro bien estar y desarrollo integral, a nivel individual y social, de anhelos, sueños y utopías que llenen de desafíos y proyectos nuestras existencias, de otra forma avanzamos sin rumbo, sin brújula y navegamos como perdidos en los mares del sin sentido.

Dotar de sentido nuestra existencia es algo que llena de dicha y alegría al alma humana. Por todo lo expuesto, postulo que este nuevo ocio puede llegar a ser uno de los elementos decisivo en este viraje existencial frente a los desafíos actuales, que de no ser superados se avizoran tiempos de mucho sufrimiento y de grandes colapsos ecológicos y sociales. 


\section{Bibliografía}

Aarendt, Hannah (1993), A condição humana. Forense Universitária, Rio de Janeiro.

Bramante, Antonio Carlos (1998), Lazer, concepções e significados. Revista Licere, v1, n1: p. 9-17. CELAR, UFMG, Belo Horizonte.

Butler, George D. (1973), Recreação. Editora Lidador Ltda., Rio de Janeiro.

Calvo, Carlos (2007), Del mapa escolar al território educativo: Disoñando la escuela desde la educación. Ediciones Nueva Mirada, Chile.

Cuenca, Manuel (2008), Ocio Humanista. En: Cuenca Cabeza, Manuel; MARTINS, J. Clerton (Organizadores). Ocio para viver no século XX: págs. 33-55. As Musas, Fortaleza.

De Grazia, Sebastian (1966), Tiempo, trabajo y ocio. Editorial Tecnos, Madrid.

Diccionario Real Academia Española. http://www.rae.es Acceso el 27 agosto de 2009.

Dumazedier, Joffre (1973), Lazer e cultura popular. Perspectiva, São Paulo.

Idem (1979), Sociologia empírica do lazer. Perspectiva, São Paulo.

Idem (1980), Valores e Conteúdos Culturais do Lazer. SESC, São Paulo.

Elizalde, Rodrigo (2008a), "Responsabilidad Social Empresarial y gestión sustentable de recursos naturales”. CICE, Santiago. págs. 51-55, En: Wilson, Ronald y Caro, Pamela (organizadores) Sistematización Encuentro Nacional Ciudadanía y Responsabilidad Social Empresarial: Balance de experiencia y desafíos de organizaciones de la Sociedad Civil. Disponible en: http://www.ciceenlinea.cl/intranet/acolumna/documento_ encuentro_final.pdf

Idem (2008), El ocio entendido desde la teoría del desarrollo a escala humana: Buscando experiencias de aprendizajes para la transformación social. Disponible en: http://www.redcreacion.org/documentos/congreso10/ RElizalde.html Acceso el 20 de abril de 2009.

Idem (2009), Ocio y aprendizaje transformacional: “Disoñando” nuevos mundos posibles. Ponencia presentada en "VI Simposio Nacional de Investigación y Formación en Recreación”, 6, 7 y 8 de agosto de 2009, Bogotá, Colombia. Pronta a ser publicada en: www.funlibre.org

Gaelzer, Lenea (1979) Lazer. Bênção o maldição? Sulina, Porto Alegre. 
Gomes, Christianne (2004), “Conceptos: Lazer - Concepções”. p. 121126; Lazer - Ocorrência histórica. págs. 133-141; Lúdico. págs. 141-146. En: Gomes, Christianne (Organizadora) Dicionário crítico do lazer. Autêntica Editora, Belo Horizonte.

Idem (2007), “O ócio como objeto de estudos: Notas introdutórias sobre conceitos e ocorrência histórica em nossa sociedade”. En: Cuadernos de Ocio y Sociedad: págs. 23-40. Nos 1-2. Corporación Civitas, Medellín.

Idem (2008), Lazer, Trabalho e Educação: Relações históricas, questões contemporâneas. Editora UFMG, Belo Horizonte.

Gomes, Christianne; Elizalde, Rodrigo (2009), “Trabajo, tiempo libre y ocio en la contemporaneidad: Contradicciones y desafíos”. En: Revista Polis $N^{o}$ 22. Universidad Bolivariana, Santiago. http://www.revistapolis.cl/ polis\%20final/22/art14.htm Acceso el 30 de abril de 2009.

Gomes, Christianne; Melo, Victor A. (2003), “Lazer no Brasil: trajetória de estudos, possibilidades de pesquisa”. Revista Movimento. Porto Alegre, v.9, n.1. págs. 23-44.

Gomes, Christianne; Pinto, Leila M. (2009), “O Lazer no Brasil: Analisando prácticas culturais cotidianas, acadêmicas e políticas”. En: Gomes, Christianne L.; Osorio, Esperanza; Pinto, Leila M.; Elizalde, Rodrigo. (Organizadores). Lazer na América Latina/Tiempo libre, ocio y recreación en Latinoamérica. Editora UFMG, Belo Horizonte, (en imprenta).

Giddens, Anthony (1994), Capitalismo e moderna teoria social. Editorial Presença, Lisboa.

Magnani, José Guilherme (2000), “Lazer, um campo interdisciplinar de pesquisa”. En: Bruhns, Heloisa T.; Gutierrez, G. L. (Organizadores). O corpo e o lúdico: Ciclo de debates lazer e motricidade. Campinas: Autores Associados/Faculdade de Educação Física-Unicamp, págs. 19-33.

Marcellino, Nelson (1987), Lazer e Educação. Editora Papirus, Campinas.

Marina, José Antonio (2002), “Concepto Interculturalidad”. En: CONILL (Organizador) Glosario para una sociedad intercultural. p. 222-228. Bancaza, Valencia.

Max-Neef, Manfred; Elizalde, Antonio; Hopenhayn, Martín (1986), Desarrollo a Escala Humana: Una opción para el futuro. Número especial de la Revista Development Dialogue. Cepaur, Santiago, Chile - Fundación Dag Hammarskjöld, Uppsala, Suecia.

Morin, Edgar (1988), El método: El conocimiento del conocimiento. Cátedra, Madrid. 
Osorio, Esperanza (2009), “La recreación en Colombia: Un campo en construcción”. En: Gomes, Christianne; Osorio, Esperanza; Pinto, Leila M., Elizalde, Rodrigo (Organizadores). Lazer na América Latina/Tiempo libre, ocio y recreación en Latinoamérica. Editora UFMG, Belo Horizonte (en imprenta).

Parker, Stanley (1978), Sociología do lazer. Zahar, Rio de Janeiro.

Racionero, Luis (1983), Del paro al ocio. Anagrama, Barcelona.

Requixa, Renato (1977), O lazer no Brasil. Brasiliense, São Paulo.

Reid, Andrés; Leiva, Roberto; Elizalde, Rodrigo (2009), “La recreación en Chile: Una mirada desde la actualidad y la precariedad”. En: Gomes, Christianne; Osorio, Esperanza; Pinto, Leila M.; Elizalde, Rodrigo. (Organizadores). Lazer na América Latina/Tiempo libre, ocio y recreación en Latinoamérica. Editora UFMG, Belo Horizonte, (en imprenta).

Rhoden, Leda (2008), “Ocio construtivo e o desenvolvimento humano”. En: Cuenca, Manuel; Martins, J. Clerton, (Organizadores), Ocio para viver no século XXI. págs. 57-78. As Musas, Fortaleza.

Suarez, Silvana (2009), “Una aproximación de la representación social de la recreación en Argentina: Aportes para resignificar el concepto”. En: Gomes, Christianne; Osorio, Esperanza; Pinto, Leila M.; Elizalde, Rodrigo, (Organizadores), Lazer na América Latina/Tiempo libre, ocio y recreación en Latinoamérica. Editora UFMG, Belo Horizonte, (en imprenta).

SERNAM (2007), Valorización del Trabajo Doméstico No Remunerado: Encuesta de Uso del Tiempo. Instituto del Trabajo, la Seguridad Social y la Empresa (TRASSE) de la Universidad Bolivariana y la Corporación DOMOS. Este estudio, de propiedad de Servicio Nacional de la Mujer de Chile, SERNAM, fue realizado el año 2007. No ha sido publicado.

Ziperovich, Pablo Carlos; Chervin, Cintia (2005), "Del ocio a la recreación en la actualidad”. En: Tabares Fernández, José Fernando; Ossa Montoya, Arley Fabio; Molina Bedoya, Victor Alonso, (Organizadores), El ocio, el tiempo libre y la recreación en América Latina: problematizaciones y desafíos: págs. 195-209. Civitas, Colombia. 